\title{
The association of the slow acetylator phenotype with bladder cancer
}

\author{
D A P EVANS, L C EZE*, AND E J WHIBLEY
}

From the Nuffield Unit of Medical Genetics, Department of Medicine, University of Liverpool, Liverpool L69 $3 B X$.

SUMMARY There is an association between exposure to aromatic amines and the development of bladder cancer. Aromatic amines such as are known to occur in tobacco smoke are polymorphically acetylated. One hundred bladder cancer patients have been acetylator phenotyped. Only three of them were non-smokers at the time of diagnosis. This new series, together with four previous series (each with its own control), have been statistically analysed together.

The result shows a significant association between the slow acetylator phenotype and bladder cancer. The slow acetylator phenotype is associated about $39 \%$ more with bladder cancer than is the rapid acetylator phenotype. This association can be interpreted in one of two ways: (1) rapid acetylators may be protected against developing bladder cancer because they are better able to render amines non-carcinogenic by acetylation, or (2) slow acetylators have greater survival with bladder cancer than rapid acetylators. Further evidence will be required to differentiate between these alternatives.

A key biological puzzle is to understand how a known environmental agent reacts with a genetic polymorphism in such a manner that some subjects of a given phenotype are more prone to develop a particular disorder. Bladder cancers are known to occur at a higher rate in subjects exposed to aromatic amines either in tobacco smoke or in their occupations. ${ }^{1}$

It has been found in both human and rabbit populations that some carcinogenic aromatic amines (for example, amino-fluorene, benzidine, and 2naphthyl-amine) are polymorphically acetylated by the same $\mathrm{N}$-acetyl-transferase that is responsible for the polymorphic acetylation of a number of drugs. $^{2}{ }^{3}$ In this genetic polymorphism slow acetylation is an autosomal recessive phenotype. ${ }^{4}$ These considerations have led to the suggestion that the two human acetylator phenotypes may differ in their predisposition to develop neoplastic disorders believed to be caused by aromatic amines. This idea is based on an analogy with the now established fact that genetic constitution can predispose to drug toxicity. ${ }^{5}$ An obvious example to test the hypothesis is bladder cancer.

*Now at Department of Biochemistry, University of Nigeria, Nsukka, Nigeria.

Received for publication 24 December 1982.

Accepted for publication 1 March 1983.
Three previous publications ${ }^{6-8}$ give information on acetylator phenotypes of bladder cancer patients. More information is needed to reach a valid conclusion. This article reports the acetylator phenotypes

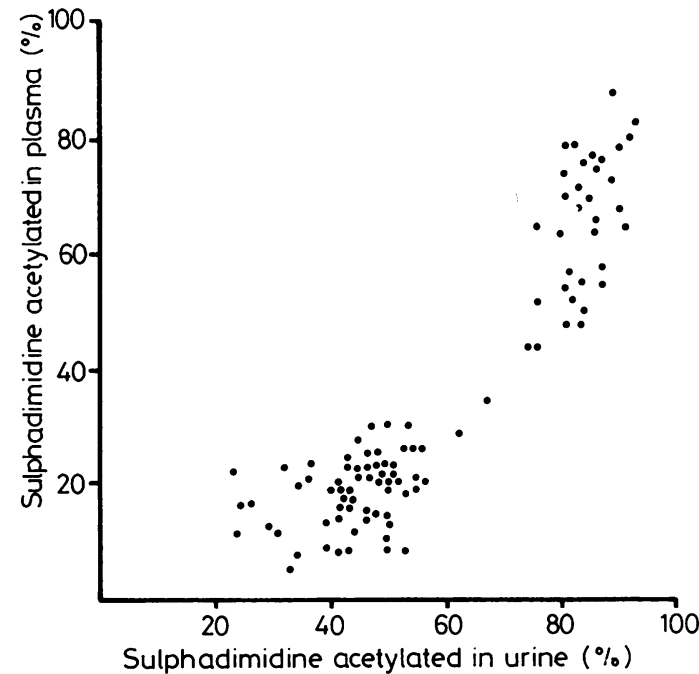

FIGURE The results of acetylator phenotyping 100 patients with bladder cancer. Rapid acetylators are defined as having an ordinate value $>40$ and an abcissa value $>70$, whereas slow acetylators have values below these limits. 
TABLE 1 Bladder cancer patients subdivided by clinical criterion and acetylator phenotype.

\begin{tabular}{|c|c|c|c|}
\hline Clinical criterion & $\begin{array}{l}\text { Slow } \\
\text { acetylators }\end{array}$ & $\begin{array}{l}\text { Rapid } \\
\text { acetylators }\end{array}$ & $\gamma_{1}^{2}$ \\
\hline \multicolumn{4}{|l|}{ Age at diagnosis } \\
\hline$<50$ & 6 & 2 & With Yates \\
\hline 50 and over & 60 & 32 & 0.029 \\
\hline \multicolumn{4}{|l|}{ Sex } \\
\hline Male & 45 & 29 & With Yates \\
\hline Female & 21 & 5 & $2 \cdot 58$ \\
\hline \multicolumn{4}{|l|}{ Smoking } \\
\hline$>20 \mathrm{cigs} / \mathrm{day}$ & $29 *$ & 15 & 0.057 \\
\hline$<20 \mathrm{cigs} /$ day & 31 & 17 & \\
\hline \multicolumn{4}{|l|}{ Industrial exposure } \\
\hline Has occurred & $11 \dagger$ & 8 & 0.943 \\
\hline Has not occurred & 44 & 19 & \\
\hline \multicolumn{4}{|l|}{ Bladder cancer $\ddagger$} \\
\hline Grade 1 & 40 & 20 & $0 \cdot 16$ \\
\hline Grades 2, 3, 4 & 20 & 12 & \\
\hline
\end{tabular}

For each row $\mathrm{p}=0 \cdot 10$.

*In addition to the 92 cigarette smokers in the table there were also 5 pipe smokers and 3 non-smokers.

tIn addition to the 19 employed in the chemical, dye, and rubber industries, there were another 18 whose exposure status was uncertain (exposure to paint solvents and engine oils and domicile next to chemicals factory).

$¥$ No histology available on 6 patients; one had squamous metaplasia and another transitional cell papilloma on histology but diagnosed as cancer of the bladder on other evidence.

of a series of bladder cancer patients and analyses all the available data.

\section{Patients}

Patients treated for bladder cancer were obtained from a register held in the Regional Urology Unit at the Royal Liverpool Hospital. These patients are admitted for periodic cytoscopic examination.
They were non-random in several ways. They were survivors whose dates of birth varied from 1903 to 1953. Their year of diagnosis varied from 1964 to 1981. Their age at diagnosis varied from 23 to 73 years. They were further selected because they lived within 10 miles of this Department and because they agreed to participate in this experiment. All were tested between April and September 1982. Their phenotyping test was carried out at their home. All patients and their family doctors gave informed consent for the phenotyping procedure to be carried out.

\section{Materials and methods}

The phenotyping procedure used was method II of Evans ${ }^{9}$ which involves giving one oral dose of sulphadimidine (syn: sulfamethazine) and taking one blood and one urine specimen for analysis. The laboratory analytical procedure was carried out as described by Eze and Evans. ${ }^{10}$

\section{Results}

One hundred patients were phenotyped (figure). The pattern of the percentage acetylation of sulphadimidine in plasma and urine closely resembled that published for normal subjects (see, for example, Viznerova et $a l^{11}$ ).

Sixty-six patients were slow acetylators giving as the frequency of the recessive allele $\mathrm{q}=0.81 \mathrm{se}(\mathrm{q})=$ 0.03 (see Karim et al ${ }^{12}$ for comparative data). The mean age at diagnosis was not significantly different

IABLE 2 Test of association between bladder cancer and acetylator phenotype. (Modification by Haldane ${ }^{15}$ of the method of Woolf $^{14}$ )

\begin{tabular}{|c|c|c|c|c|c|c|c|c|c|}
\hline \multirow[t]{3}{*}{ Reference } & \multicolumn{4}{|c|}{ No of subjects } & \multirow{3}{*}{$\begin{array}{l}\text { Approximate } \\
\text { relative } \\
\text { risk } x\end{array}$} & \multirow{3}{*}{$\begin{array}{l}\log _{e} x \\
=y\end{array}$} & \multirow{3}{*}{$\begin{array}{l}\text { Sampling } \\
\text { variance } \\
V\end{array}$} & \multirow{3}{*}{$\begin{array}{l}\text { Weight } \\
\frac{l}{V}==w\end{array}$} & \multirow{3}{*}{$\begin{array}{l}\text { Significance } \\
\text { of difference } \\
\text { from zero wy }\end{array}$} \\
\hline & \multicolumn{2}{|c|}{ Bladder cancer } & \multicolumn{2}{|c|}{ Controls } & & & & & \\
\hline & Slow & Rapid & Slow & Rapid & & & & & \\
\hline Lower et al 6 Danish* & 46 & 25 & 38 & 36 & $1 \cdot 7288$ & $0 \cdot 5474$ & $0 \cdot 1124$ & $8 \cdot 8963$ & $2 \cdot 6657$ \\
\hline Lower et al 6 Swedish* & 80 & 35 & 79 & 39 & $1 \cdot 1267$ & 0.1193 & 0.0776 & $12 \cdot 8827$ & $0 \cdot 1834$ \\
\hline Cartwright et $a^{8+}$ & 74 & 37 & 118 & 89 & $1 \cdot 4921$ & 0.4002 & 0.0592 & $16 \cdot 9016$ & $2 \cdot 7054$ \\
\hline Woodhouse et $\mathrm{all}_{+}^{7 \pm}$ & 21 & 9 & 16 & 13 & $1 \cdot 8517$ & 0.6161 & 0.2757 & $3 \cdot 6270$ & $1 \cdot 3767$ \\
\hline Present series & 66 & 34 & $510 \S$ & 342 & $1 \cdot 2932$ & 0.2571 & 0.0484 & $10 \cdot 6748$ & $1 \cdot 3666$ \\
\hline
\end{tabular}

Weighted mean value of $y=Y=\frac{\sum w y}{\sum w}=\frac{20 \cdot 7208}{62 \cdot 9824}=0 \cdot 3290$.

$\mathrm{SE}$ of $\mathrm{Y}=(\Sigma \mathrm{w})^{-\frac{1}{2}}=0 \cdot 1260$.

$95 \%$ fiducial limits of $\mathrm{Y}=\mathrm{Y} \pm \mathrm{t}_{4} 0.05(\mathrm{Vw})^{-\frac{1}{2}}=\mathrm{Y}+(2.78 \times 0.126)=0.6793$ and -0.0213 .

Antilog of $Y=X=$ combined estimate of values of $X=1 \cdot 389$.

The equivalent $X$ values to the $95 \%$ fiducial limits of $Y$ are 1.9725 and 0.9789 .

Significance of difference of $X$ from unity $=\chi_{1}^{2}=\frac{\left(\sum w y\right)^{2}}{\Sigma w}=6.8170(p<0.01)$.

Heterogeneity is tested by $\chi^{2} N_{-1}=\Sigma w y^{2}-\frac{(\Sigma w y)^{2}}{\Sigma w}=1.4824(p>0 \cdot 10)$.

*Technique of phenotyping : Weber and Brenner. 26

$\uparrow$ Technique of phenotyping : monoacetyl dapsone/dapsone ratio in plasma.

$¥$ Technique of phenotyping : plasma isoniazid half life.

§Pooled Liverpool control data. 
in the two phenotypes $(57 \cdot 3$ years in the slow and 58.6 in the rapid).

These patients have been sub-divided in relation to various characteristics (sex, age, smoking, history of industrial exposure, and histological type of bladder neoplasm) (table 1). In no case was there any hint of association with the acetylator polymorphism. At the time of diagnosis only three patients were non-smokers. There are no satisfactory control data available on the relationship between smoking habits and the acetylator polymorphism. Several retrospective studies have indicated that cigarette smokers have approximately twice the risk of non-smokers of cancer of the bladder. ${ }^{13}$ Positive industrial exposure was principally in the chemical and rubber industries were amines are known to have been employed. The 19 persons deemed to have been 'exposed' had worked in the rubber and chemical industries for varying periods most for many years. Two had worked in these industries for less than 7 years, one for 5 months, and one for 12 months.

The present results, together with four previously available series, have been examined by the method of Woolf ${ }^{14}$ as modified by Haldane ${ }^{15}$ (table 2).

Suitable control information for the present bladder cancer patients has been obtained by pooling data which have previously been published on several series of Liverpool white British subjects. ${ }^{9}$ (series I) 10 16-25 There is a highly significant association between bladder cancer and the slow acetylator phenotype and there is no heterogeneity between the results from different series.

\section{Discussion}

The information shown in the figure closely resembles the results obtained when populations of healthy subjects have been phenotyped using the same technique, which is evidence indicating that any residual activity of bladder cancer did not interfere with the phenotyping test.

In studies of statistical associations of genetically determined phenotypes with disorders, the matter of selection is of importance. The Liverpool bladder cancer patients were people who had survived over a period and who lived in a defined area, so selection factors might have been introduced. It is possible that the survival factor might influence the results in other studies in table 2.

Another point of great importance is the nature of the control populations. Two separate sets of controls were studied by Lower et al. ${ }^{6}$ Each separate study has its own control group and the sets of controls were non-random and collected in different ways, one set to accompany the urban Copenhagen patients and another to accompany the rural Lund patients. In each case the controls were "healthy hospital personnel and hospital patients". A series of geriatric patients without malignant disease constituted the controls of Woodhouse et al. ${ }^{7}$ The London-based controls of Cartwright et $a l^{8}$ were "healthy subjects from Guy's Hospital", and the Huddersfield controls were either non-bladder cancer urological patients or "patients undergoing cold surgery for various conditions". The six Liverpool control series which were pooled comprised variously healthy medical students, healthy hospital and university staff, and tuberculous patients. It may be speculated that the lack of heterogeneity of the association between the series (table 2) is more convincing in view of the differing nature of the control groups.

Cartwright et $a l^{8}$ observed a strikingly high association between the slow acetylator phenotype and bladder cancer in Huddersfield dye workers. No such sub-group of occupational exposure could be defined in the present series where persons had been exposed to a wide variety of industrial chemicals. The association revealed in table 2 is clearly strengthened by the inclusion of the Huddersfield dye workers, but would still be statistically significant $(\mathrm{p}<0.05)$ if the data of Cartwright et $a l^{8}$ were omitted. Smoking would appear to be a more general environmental association (see table 1 for the data on smoking in the present series).

Table 2 reveals the slow acetylator phenotype to be about $39 \%$ more associated with bladder cancer than the rapid acetylator phenotype. Two possible interpretations follow. (1) Slow acetylators are more prone to develop bladder cancer than rapid acetylators. Carcinogenic amines (which occur in tobacco smoke) are known to be polymorphically acetylated. It is suggested, therefore, that the phenotype performing rapid acetylation of these amines may possess a degree of protection against the development of bladder cancer. (2) Slow acetylators have a greater survival with bladder cancer than rapid acetylators.

Obviously prevalence data will not allow either of these interpretations to be eliminated. It will be necessary to acetylator phenotype bladder cancer patients at the time of diagnosis in order to resolve the difficulty. The association shown in table 2 is sufficiently firm to justify such an undertaking.

\section{Addendum}

After this article had been submitted Miller (Miller ME. Acetylator phenotype in bladder cancer. Lancet 1982; ii: 1348) reported the acetylator phenotypes of 15 bladder cancer patients who had a 
positive occupational exposure to bladder carcinogens. Six were slow acetylators. There was no control group.

The authors wish to thank many family doctors, $\mathrm{Mr} \mathrm{N} O \mathrm{~K}$ Gibbon, Mr R Jameson, and Miss C M Evans (consultant urologists), and Dr Mavis McConnell (consultant histopathologist) for access to and information on patients with cancer of the bladder, and Dr D Y Downham, Department of Statistics and Computational Mathematics, University of Liverpool, for advice on statistical aspects.

\section{References}

1 Manson D. Some illustrative systems of chemical carcinogenesis (2) aromatic amines. In: Symington T, Carter RL, eds. Scientific foundations of oncology. Chap 34. London: Heinemann, 1976:281-91.

2 Glowinski IB, Radtke HE, Weber WW. Genetic variation in $\mathrm{N}$-acetylation of carcinogenic arylamines by human and rabbit liver. Mol Pharmacol 1978;14:940-9.

3 Glowinski IB, Weber WW. Genetic regulation of aromatic amine $\mathrm{N}$-acetylation in inbred mice. $\mathrm{J}$ Biol Chem 1982;257:1424-30.

4 Evans DAP, Manley KA, McKusick VA. Genetic control of isoniazid metabolism in man. Br Med $J$ 1960; ii:485-91.

5 Glowinski IB, Weber WW, Fysh JM, Vaught JB, King CM. Evidence that arylhydroxamine acid, N,O-acyltransferase and the genetically polymorphic $\mathrm{N}$-acetyltransferase are properties of the same enzyme in rabbit liver. J Biol Chem 1980;255:7883-90.

6 Lower GM Jr, Nilsson T, Nelson CE, Wolf H, Gamsky TE, Bryan GT. N-acetyltransferase phenotype and risk in urinary bladder cancer: approaches in molecular epidemiology. Preliminary results in Sweden and Denmark. Environ Health Perspect 1979;29:71-9.

7 Woodhouse KW, Adams PC, Clothier A, Mucklow JC, Rawlins MD. N-acetylation phenotype in bladder cancer. Hum Toxicol 1982;1:443-5.

8 Cartwright RA, Glashan RW, Rogers HJ, et al. Role of $\mathrm{N}$-acetyltransferase phenotypes in bladder carcinogenesis: a pharmacogenetic epidemiological approach to bladder cancer. Lancet 1982 ;ii:842-5.

9 Evans DAP. An improved and simplified method of detecting the acetylator phenotype. J Med Genet 1969; 6:405-7.

10 Eze LC, Evans DAP. The use of the Autoanalyser to determine the acetylator phenotype. J Med Genet 1972; 9:57-9.
11 Viznerova A, Slavikova Z, Ellard GA. The determination of the acetylator phenotype of tuberculosis patients in Czechoslovakia using sulphadimidine. Tubercle 1973; 54:67-76.

12 Karim AKMB, Elfellah MS, Evans DAP. Human acetylator polymorphism: estimate of allele frequency in Libya and details of global distribution. J Med Genet $1981 ; 18: 325-30$.

13 Report of the Royal College of Physicians of London. Smoking and health now. London: Pitman, 1971:97.

14 Woolf B. On estimating the relation between blood group and disease. Ann Hum Genet 1955;19:251-3.

15 Haldane JBS. The estimation and significance of the logarithm of a ratio of frequence. Ann Hum Genet 1955; 20:309-11.

16 Evans DAP, White TA. Human acetylation polymorphism. J Lab Clin Med 1964;63:394-403.

17 Gow JG, Evans DAP. A study of the influence of the isoniazid inactivator phenotype on reversion in genitourinary tuberculosis. Tubercle $1964 ; 45: 136-43$.

18 White TA, Evans DAP. The acetylation of sulfamethazine and sulfamethoxypyridazine by human subjects. Clin Pharmacol Ther 1968;9:80-8.

19 Price J. Demethylation, methylation and schizophrenia. A pharmacogenetic study. MD thesis, University of London, 1971.

20 Evans DAP, Bullen MG, Houston J, Hopkins CA, Vetters JM. Antinuclear factor in rapid and slow acetylator patients treated with isoniazid. J Med Genet 1972; 9:53-6.

${ }^{21}$ Schröder H, Evans DAP. The polymorphic acetylation of sulphapyridine in man. J Med Genet 1972;9:168-71.

22 Schröder H, Evans DAP. Acetylator phenotype and adverse effects of sulphasalazine in healthy subjects. Gut 1972;13:278-84.

23 Schröder H, Lewkonia RM, Evans DAP. Metabolism of salicylazosulfapyridine in healthy subjects and in patients with ulcerative colitis. Clin Pharmacol Ther $1973 ; \mathbf{1 4 : 8 0 2 - 9 .}$

24 Ellard GA, Gammon PT, Tiitinen H. Determination of the acetylator phenotype using matrix isoniazid. Tubercle $1975 ; 56: 203-9$.

25 Karim AKMB, Evans DAP. Polymorphic acetylation of nitrazepam. J Med Genet 1976;13:17-9.

26 Weber WW, Brenner W. A filter paper method for determining isoniazid acetylator phenotype. $\mathrm{Am} \mathrm{J} \mathrm{Hum}$ Genet $1974 ; 26: 467-73$.

Correspondence and requests for reprints to Professor D A Price Evans, Nuffield Unit of Medical Genetics, Department of Medicine, University of Liverpool, Liverpool L69 3BX. 